\title{
EXPERIMENTAL STUDY OF AORTIC STOP-FLOW INFUSION WITH HYPOXIC ABDOMINAL PERFUSION CHEMOTHERAPY
}

\author{
Kentaro Asami, Tatsuya Aoki, Toshiaki Aoki, Akihiko Tsuchida \\ and Yasuhisa Koyanagi \\ Department of Surgery, Tokyo Medical University \\ 6-7-1 Nishi-Shinjuku, Shinjuku-Ku, Tokyo 160-0023, Japan \\ (Received on Nov. 11, 2000, accepted on Dec. 12, 2000)
}

\begin{abstract}
We evaluated the pharmacokinetics of anticancer drugs, drug concentration in tissues of the liver and the pancreas, and the hematological changes in aortic stop-flow infusion with hypoxic abdominal perfusion (ASI with HAP) using Beagle dogs under general anesthesia.

Concerning the of blood concentrations of both mitomycin $\mathrm{C}(\mathrm{MMC})$ and 5fluorouracil (5-FU), the area under the curve (AUC) with perfusion circuit (PC) in the ASI with HAP group was significantly higher than in the control group. On the contrary, there was no significant difference for AUC in the non-PC as compared with that in the control group. From these results, this method is effective to increase the blood concentration of drugs in target organs. It is suggested that the maximum dose of anticancer drugs in ASI with HAP should not greatly exceed the dose given in systemic administration by rapid intravenous injection.

Drug concentrations of both MMC and 5-FU in the ASI with HAP group were significantly higher than those in the control group in the liver and in the pancreas. Concentrations of MMC and 5-FU in hepatic tissue were lower than those in pancreatic tissue, and there was a tendency for the concentration in hepatic tissue to decline more rapidly in comparison of pancreatic tissue. This is ascribed to the fact that the catabolism of both agents occurs mainly in the liver.

The measurements of blood gas indicated that a hypoxic condition was maintained only in PC, and PC became lower in $\mathrm{pH}$ during perfusion. The results of blood biochemical examinations revealed that the variations in each parameter peaked between 15 and 30 minutes after completion of perfusion and that they all reached a plateau 60 minutes after completion. The increases of hepatic enzymes such as AST, ALT and LDH were ascribed to ischemia due to the aorta stop-flow and to the reperfusion injury of the liver following release of stop-flow. Superoxide dismutase
\end{abstract}

Correspondence to: Dr. Kentaro Asami, Department of Surgery, Tokyo Medical University, 6-7-1 Nishi-Shinjuku, Shinjuku-Ku, Tokyo 160-0023, Japan. Phone: 81-33342-6111 Ext. 5080, FAX: 81-3-3340-4575 
(SOD) exhibited a sharp increase immediately after administration of anticancer drugs, which was ascribed to the influence of MMC administration. However, these biochemical changes in ASI with HAP were believed to be reversible and of short duration.

\section{Introduction}

Local perfusion chemotherapy was first applied for colon, uterine, and breast cancer using nitrogen mustard by (Creech, Krementz et al., 1958). In Japan, clinical reports of this procedure were submitted by (Fujimori, Sakauchi et al., 1963) and by (Sakauchi, Ukishima et al., 1963). From 1970, however, although this therapy was continued in part in the field of orthopedic surgery, there have been no reports in Europe, the United States or Japan on this therapy for abdominal tumors, except for cases of blood flow occlusion of the liver only ( $\mathrm{Ku}$, Saitoh, et al., 1991). The reasons were as follow; 1) Occlusion of local blood flow in the open laparotomy might be difficult in some patients with specific conditions. 2) Repeated execution under relaparotomy might be difficult, because patients sometimes had a severe abdominal adhesion. 3) According to the development of new apparatus such as an implanted port for arterial chemotherapy (Miura, Idezuki, et al., 1985; Miura, 1989; Idezuki and Miura, 1990), high concentrations of anticancer agents could be administered to target organs. Aigner and Gailhofer, (1993) newly invented a stop-flow catheter which enabled recurrent performance of intraabdominal blood flow occlusion and anticancer drug infusion without laparotomy (Aigner, 1993; Aigner and Gailhofer, 1993; Aigner and Kaevel, 1994). This method is called aortic stop-flow infusion with hypoxic abdominal perfusion (ASI with HAP), and it was used in other countries thereafter (Thompson, Liu, et al., 1994; Fiorentini, Poddie, et al., 1996; Roversi, Roversi, et al., 1996-1998), but there was hardly any investigation of basic pharmacokinetics or circulatory kinetics. Thus, in the present study, an aortic stop-flow perfusion model was compiled using dogs, and we evaluated the pharmacokinetics following administration of anticancer drugs, drug concentration in tissue, and the hematological changes through comparisons with a control group.

\section{Materials and methods}

Animals and operative procedure

Twenty-one Beagle dogs at an average body weight of $10.3 \mathrm{Kg}$ were used as materials, and they were handled in accordance with guidelines of the Institutional 
Animal Care and Ethical Committee of Tokyo Medical University. Following intramuscular injection of $0.5 \mathrm{mg} / \mathrm{Kg}$ of ketamine hydrochlomide and intravenous injection of $0.1 \mathrm{mg} / \mathrm{Kg}$ of pancuronium bromide, endotracheal intubation was performed. Then semi-closed anesthesia apparatus was connected, and respiration at 50\% oxygen concentration was controlled artificially. For maintaining anesthesia, isoflurane was used with nitrous oxide.

For the stop-flow catheter in ASI with HAP, we newly developed 7Fr. double lumen blood vessel stopped catheter with balloon (Clinical Supply Co., Tokyo, Japan). An incision was made at the right femoral region, and catheters were inserted into each femoral vessels after systemic administration of heparin sodium $1000 \mathrm{U} /$ body. By balloon catheters blood flows were stopped both in the abdominal aorta above the celiac bifurcation and in the inferior vena cava above the hepatic vein access under X-ray imaging. At the same time, the lower extremities were avascularized at the periphery from the catheter using tourniquet. Blood flow occlusion was confirmed by injecting contrast medium into catheter (Figure 1). Immediately after blood flow occlusion, intraabdominal perfusion was begun using Biopump(r) (Medtronic Co., Minneapolis, USA) with taking blood from the venous side catheter and reinfusion toward the arterial catheter. Fifteen minutes after the start of perfusion, $0.4 \mathrm{mg} / \mathrm{Kg}$ of Mitomycin C (MMC) and $10 \mathrm{mg} / \mathrm{Kg}$ of 5-fluorouracil (5-FU) with physiological saline as a total volume of 50 $\mathrm{ml}$ were administered into the reinfusion route by bolus injection. After this perfusion was continued for 30 minutes at a flow volume of $200 \mathrm{ml} / \mathrm{min}$, the blockage of blood flow was released (Figure 2).

\section{Examination of pharmacokinetics of anticancer drugs}

ASI with HAP was performed on 11 animals (ASI with HAP group) and the concentrations of MMC and 5-FU in blood, in hepatic and pancreatic tissue were examined. For the control group, the same doses of anticancer drugs were administered by intravenous bolus injection to 10 animals. Blood samples were taken $5,10,15,20,30$, 45 and 60 minutes after administration. In the ASI with HAP group, blood samples were taken from the outflow route of the perfusion circuit (PC) for the duration of perfusion 5, 10 and 15 minutes after administration. Blood samples from the non-perfusion circuit (non-PC) were taken from the arterial line in the forelimb. After completion of perfusion, 


\section{ANNALS OF Cancer Research and Therapy}

blood samples were taken only from the arterial line in the forelimb. In the control group, blood samples were taken from the fore limb arterial line. Several grams each of hepatic and pancreatic tissue samples were excised 5 and 15 minutes after administration under laparotomy. Immediately after retrieval, blood samples were centrifugalized for 3 minutes at 3000 r.p.m. and the extracted serum was frozen at $-80^{\circ} \mathrm{C}$. Immediately after retrieval, tissue samples were also frozen at $-80^{\circ} \mathrm{C}$ and stored.

Concentrations were measured by high-performance liquid chromatography (HPLC) assay (Shimadzu Co., Tokyo, Japan). MMC concentration; $2.5 \mu \mathrm{g} / \mathrm{ml}$ of Porfiromycin $-0.01 \mathrm{M}, 100 \mu \mathrm{l}$ of citrate buffer solution ( $\mathrm{pH} 6.5$ ) and $8 \mathrm{ml}$ of ethyl acetate were added to $0.5 \mathrm{ml}$ of MMC as standard internal substances, which was then mixed in blood serum. After extraction, the organic layer was separated centrifugally and subjected to concentrate and exsiccate. Then this material was redissolved in addition with $0.5 \mathrm{ml}$ of $0.01 \mathrm{M}$ citrate buffer solution ( $\mathrm{pH} 6.5$ ), and the centrifugually separated supernatant was provided for measurement. With respect to tissue, $2.5 \mu \mathrm{g} / \mathrm{ml}$ of Porfiromycinacetonitrile $100 \mu \mathrm{l}$ and $3 \mathrm{ml}$ of acetonitrile were added to $0.2 \mathrm{~g}$ of tissue specimen and homogenized, and then the centrifugally separated supernatant was subjected to concentrate and exsiccate. To this was added $0.5 \mathrm{ml}$ of $0.01 \mathrm{M}$ citrate buffer solution ( $\mathrm{pH}$ 6.5 ), which was redissolved, and the centrifugally separated supernatant was provided for measurement. A calibration curve was drawn using a standard MMC solution of known concentration, and measurements were taken under the following conditions; Column: Develosil ODS T-54.6 mm x $150 \mathrm{~mm}$ (Nomura Chemical Co., Tokyo, Japan), Shift phase A: $0.01 \mathrm{M}$ citrate buffer solution $(\mathrm{pH} 6.5)+$ acetonitrile (87:13), Flow speed: $1 \mathrm{ml} / \mathrm{min}$, Detection wavelength: UV $364 \mathrm{~nm}$. 5-FU concentration; $0.5 \mu \mathrm{g} / \mathrm{ml}$ of 5-Chlorouracil $0.5 \mathrm{M}, 100 \mu \mathrm{l}$ of phosphate buffer solution $(\mathrm{pH} 8.0$ ) and $7 \mathrm{ml}$ of ethyl acetate were added to $0.2 \mathrm{ml}$ of 5 -FU as standard internal substances, which was then mixed in serum. After extraction, the organic layer was separated centrifugally and subjected to concentrate and exsiccate. To this was added $0.5 \mathrm{ml}$ of shift phase B: ethyl acetate $+\mathrm{n}$-hexane + formic acid + water (50: 50: 0.5: 0.3), which was redissolved and provided for measurement. With respect to tissue, $0.5 \mu \mathrm{g} / \mathrm{ml}$ of 5 -Chlorouracil solution $100 \mu \mathrm{l}$ and $3 \mathrm{ml}$ of acetonitrile were added to $0.2 \mathrm{~g}$ of tissue specimen and homogenized, and then the 
centrifugally separated supernatant was subjected to concentrate and exsiccate. After this was redissolved in ethanol, it was adsorbed into a silica gel column (Silica gel: 80-100 mesh column for chromatography, $500 \mathrm{mg}$; Kanto Chemical Co., Tokyo, Japan). The 5FU fraction was retrieved through acetone extraction and subjected to concentrate and exsiccate. To this was added $0.5 \mathrm{ml}$ of shift phase $\mathrm{B}$ as described above, which was redissolved and provided for measurement. A calibration curve was drawn using a standard 5-FU solution of known concentration and measurements were taken under the following conditions; Column: Develosil 60-3 $4.6 \mathrm{~mm} \times 100 \mathrm{~mm}$ (Nomura Chemical Co., Tokyo, Japan), Shift phase B: ethyl acetate $+\mathrm{n}$-hexane + formic acid + water (50: 50: 0.5: 0.3 ), Flow speed: $0.9 \mathrm{ml} / \mathrm{min}$, Detection wave length: UV $264 \mathrm{~nm}$.

The results of measurements in the ASI with HAP group were compared with in the control group for the blood concentrations of drugs, area under the curve (AUC) over 15 minutes after administration, and concentrations in hepatic and pancreatic tissue. Respecting in blood concentration and AUC, comparisons were made with the control group in both PC and non-PC. For the AUC of each group, average AUC values calculated for every sample used. For the AUC of each sample, 0 value was extrapolated in linear regression by the linear method of least squares, and using this value, the AUC was determined by trapezoidal formula. In the statistical examination, the Mann-Whitney test was used and $\mathrm{p}<0.01$ was taken as a significant difference.

\section{Examination of blood gas and biochemical kinetics}

With the ASI with HAP group above mentioned, partial pressure oxygen (pO2), power of $\mathrm{H}^{+}(\mathrm{pH})$, Base excess (BE), Superoxide dismutase (SOD), Aspartate aminotransferase (AST), Alanine aminotransferase (ALT), Lactate dehydrogenase (LDH) and Potassium $(\mathrm{K})$ were measured. These results were compared with those in the ASI with HAP group without administration of anticancer drugs as a control $(n=5)$.

Blood samples were taken before perfusion, 5, 10, 15, 20, 25 and 30 minutes after the start of perfusion, and then $5,15,30$ and 60 minutes after completion of perfusion. During perfusion, blood samples in PC were taken from the outflow route, and blood samples in non-PC were taken from the arterial line in the forelimb. After completion of perfusion, blood samples was taken from the arterial line in forelimb. 


\section{Results}

Pharmacokinetics of anticancer drugs in blood

In the ASI with HAP group, MMC concentrations $(\mu \mathrm{g} / \mathrm{ml}) 5,10$ and 15 minutes after administration were $1.65 \pm 0.26,0.94 \pm 0.14,0.54 \pm 0.14$ in PC, and $0.75 \pm 0.17$, $0.54 \pm 0.15,0.34 \pm 0.05$ in non-PC, respectively. In the control group, they were $0.72 \pm$ $0.07,0.47 \pm 0.05,0.39 \pm 0.05$, respectively. With $\mathrm{PC}$, in contrast to the control group, significantly high values were exhibited 5 and 10 minutes after administration, but no significant differences were recognized after 15 minutes (Figure 3). AUC ( $\mu \mathrm{g} \mathrm{min} / \mathrm{ml}$ ) over 15 minutes after administration was $21.5 \pm 3.0$ with PC, $10.2 \pm 2.5$ with non-PC and $9.8 \pm 0.9$ with the controls. Values with PC were significantly higher in comparison to the controls. No significant differences were noted between non-PC and in the controls (Table I).

In the ASI with HAP group, 5-FU concentrations $(\mu \mathrm{g} / \mathrm{ml}) 5,10$ and 15 minutes after administration were $33.5 \pm 6.2,27.7 \pm 5.0,20.8 \pm 3.7$ in PC, and 13.1 $\pm 3.5,10.4 \pm$ $1.6,9.7 \pm 1.6$ in non-PC, respectively. In the control group, they were $17.2 \pm 2.7,11.2 \pm$ $1.5,8.6 \pm 1.2$, respectively. With PC, in contrast to the control group, significantly high values were exhibited 5,10 and 15 minutes after administration. Between non-PC and the controls, no significant differences were recognized after 5, 10 or 15 minutes (Figure 4). AUC ( $\mu \mathrm{g} \mathrm{min} / \mathrm{ml}$ ) over 15 minutes after administration were $466 \pm 83$ in PC, $179 \pm 41$ in non-PC and $223 \pm 33$ in the controls. Values with PC were significantly higher in comparison to the controls. No significant differences were noted between in non-PC and in the controls (Table I).

\section{Drug concentrations in tissue}

MMC concentrations (ng/g) in hepatic tissue 5 and 15 minutes after administration were $156 \pm 39,80 \pm 26$ in the ASI with HAP group and $65 \pm 18,4.2 \pm 4.0$ in the control group, respectively. With the ASI with HAP group, MMC concentrations $(\mathrm{ng} / \mathrm{g}$ ) in pancreatic tissue were $280 \pm 87,228 \pm 103$, and with the control group, $91 \pm 24$, $22 \pm 13$, respectively. In the ASI with HAP group, as compared to the controls, significantly high values were exhibited 5 and 15 minutes after administration in both hepatic and pancreatic tissue (Table II). 
VOL. 8, NOS. $1 \& 2$

2000

ANNALS OF

Cancer Research and Therapy

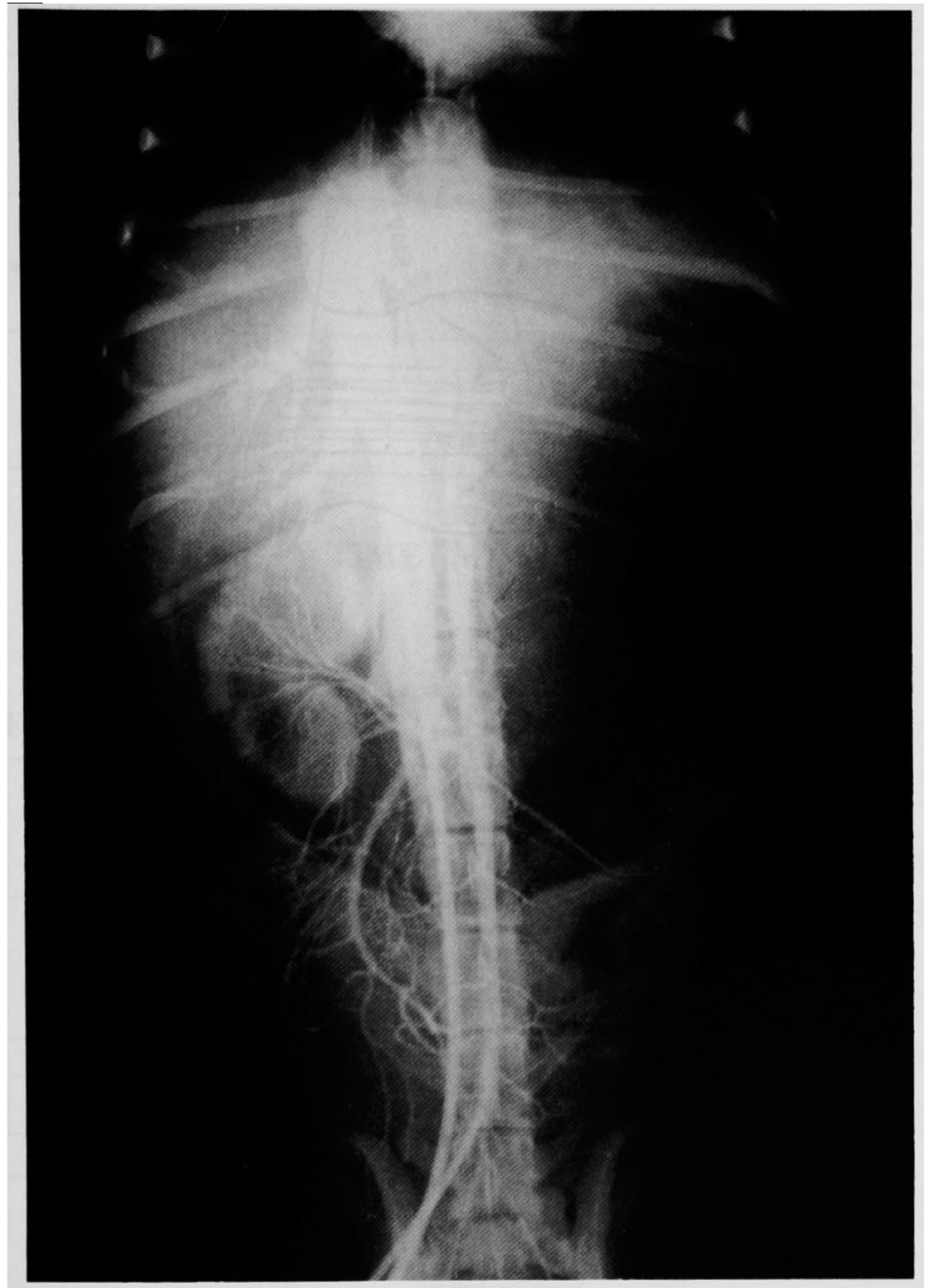

Figure 1. Abdominal angiography showing a stop of blood flow in aorta and vena cava. 
VOL. 8, NOS. 1 \& 2

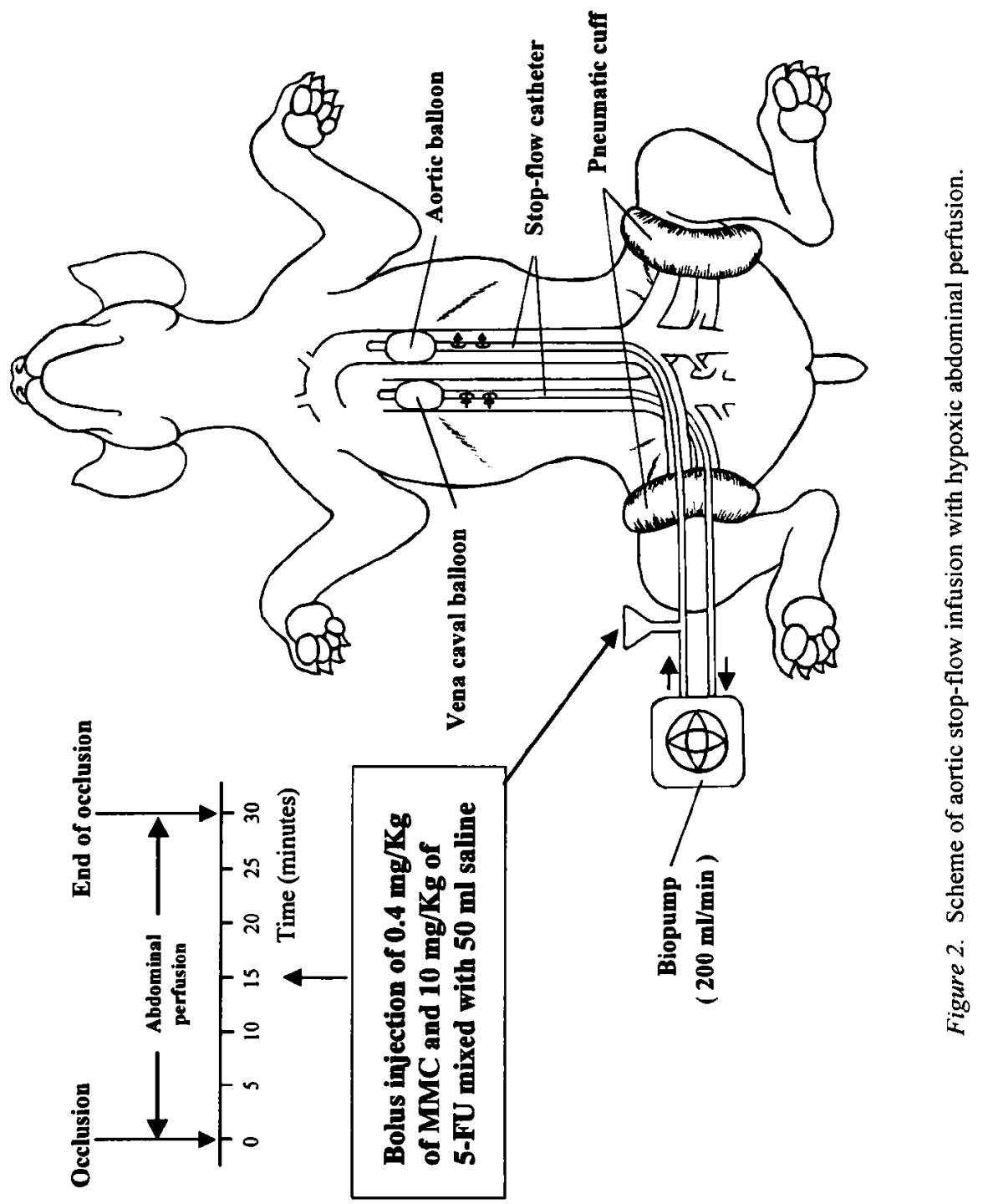


$\operatorname{MMC}(\mu \mathrm{g} / \mathrm{ml})$

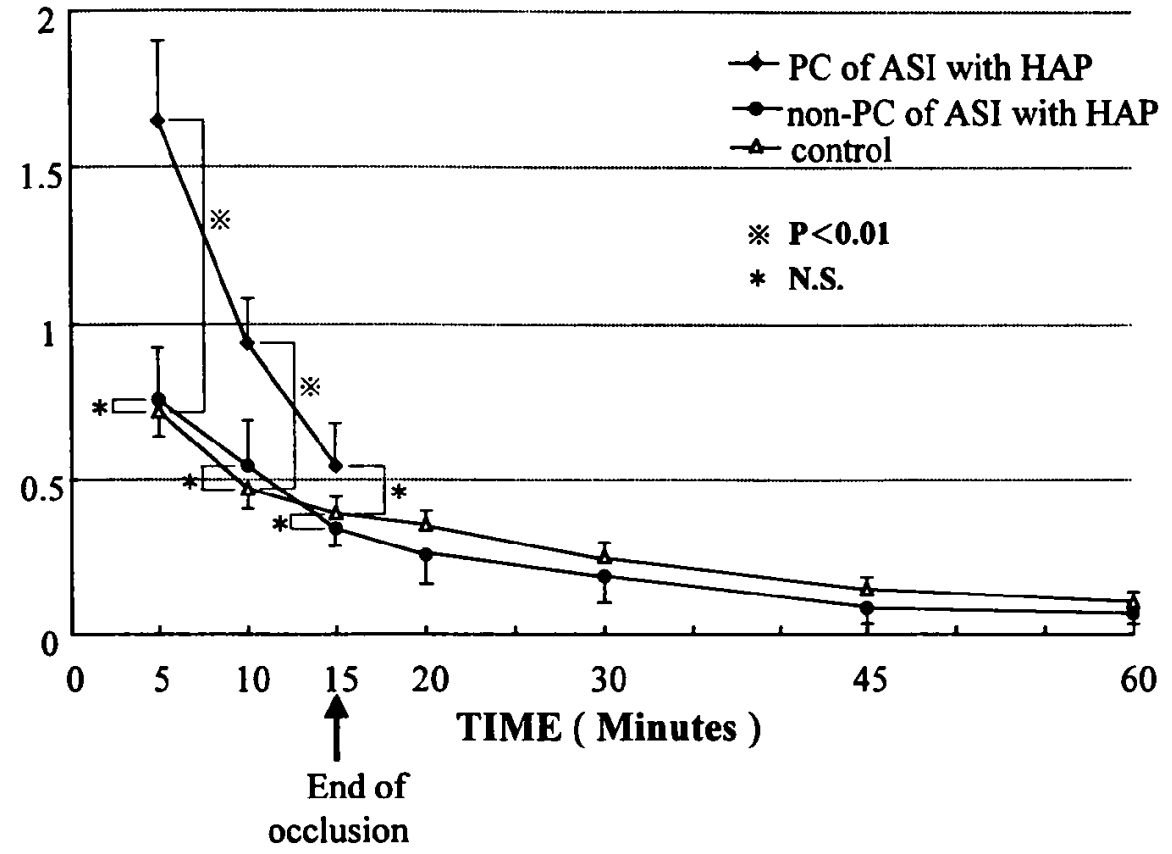

Figure 3. Blood concentrations of MMC.

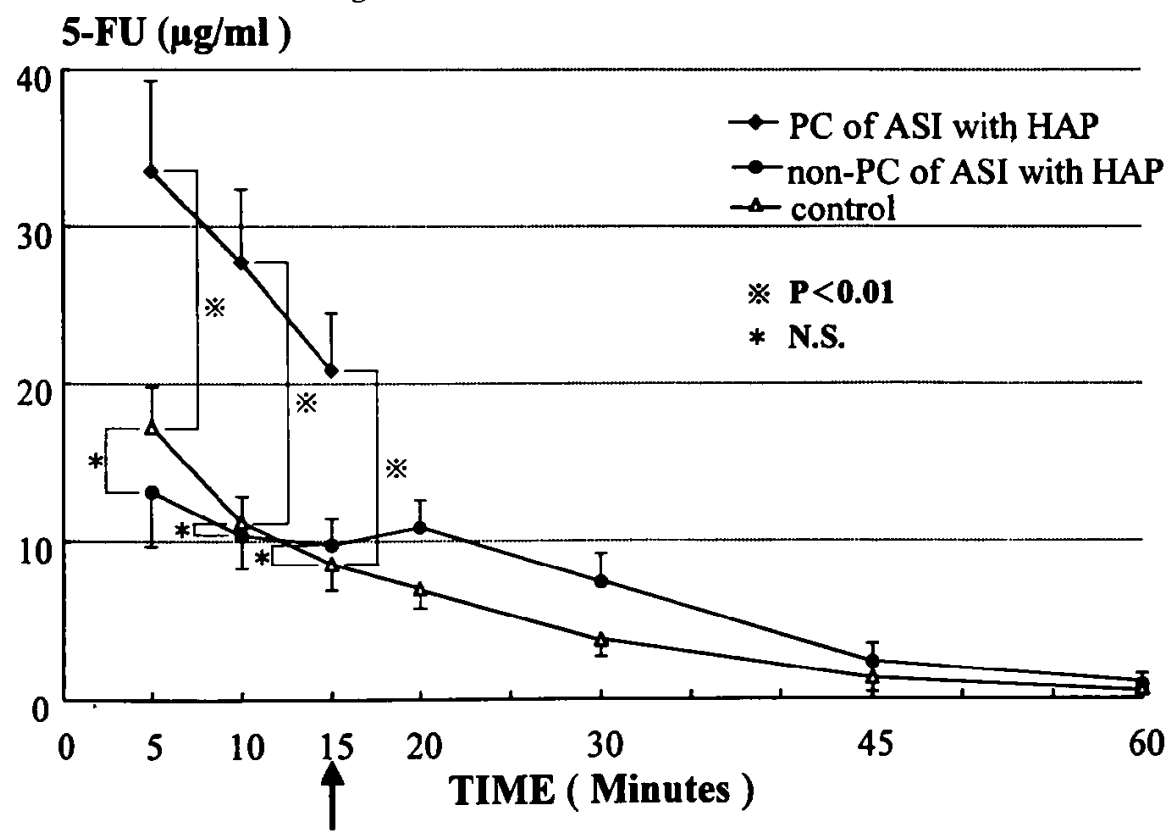

End of occlusion

Figure 4. Blood concentrations of 5-FU. 
VOL. 8, NOS. $1 \& 2$

2000
ANNALS OF

Cancer Research and Therapy

\section{TABLE I}

Area under the curve (AUC) of MMC and 5-FU during perfusion

\begin{tabular}{|c|c|c|}
\hline & \multicolumn{2}{|c|}{ AUC $0-15(\mu \mathrm{g} \cdot \mathrm{min} / \mathrm{ml})$} \\
\hline & MMC & 5-FU \\
\hline $\begin{array}{l}\text { PC of ASI with HAP } \\
\text { non-PC of ASI with HAP } \\
\text { control }\end{array}$ & 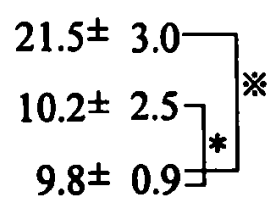 & $\left.\begin{array}{c}466 \pm 83 \\
179 \pm 41 \\
223 \pm 33\end{array}\right] *$ \\
\hline
\end{tabular}

※:P<0.01 * : N.S.

TABLE II

Concentrations of MMC and 5-FU in tissues of the liver and the pancreas

\begin{tabular}{|c|c|c|c|c|c|}
\hline & \multicolumn{2}{|c|}{$\mathrm{MMC}(\mathrm{ng} / \mathrm{g})$} & \multicolumn{2}{|c|}{ 5-FU $(\mu \mathrm{g} / \mathrm{g})$} \\
\hline & & $5 \mathrm{~min}$ & $15 \mathrm{~min}$ & $5 \mathrm{~min}$ & $15 \mathrm{~min}$ \\
\hline epatic tissue & $\begin{array}{l}\text { ASI with HAP } \\
\text { control }\end{array}$ & $\left.\begin{array}{r}156 \pm 39 \\
65 \pm 18\end{array}\right] *$ & $\left.\begin{array}{c}80 \pm 26 \\
5 \pm 4\end{array}\right] *$ & $\left.\begin{array}{l}24.9 \pm 5.5 \\
12.0 \pm 2.4\end{array}\right] \%$ & $\left.\begin{array}{l}9.0 \pm 2.3 \\
3.0 \pm 1.2\end{array}\right]$ \\
\hline & $\begin{array}{l}\text { ASI with HAP } \\
\text { control }\end{array}$ & $\left.\begin{array}{r}280 \pm 87 \\
91 \pm 24\end{array}\right] *$ & $\left.\begin{array}{c}228 \pm 103 \\
22 \pm 13\end{array}\right] *$ & $\left.\begin{array}{l}36.6 \pm 6.3 \\
16.2 \pm 4.0\end{array}\right] *$ & $\left.\begin{array}{r}27.5 \pm 5.5 \\
9.0 \pm 3.0\end{array}\right]$ \\
\hline
\end{tabular}

$*: \mathrm{P}<0.01$ 
VOL. 8, NOS. 1 \& 2

2000
ANNALS OF

Cancer Research and Therapy

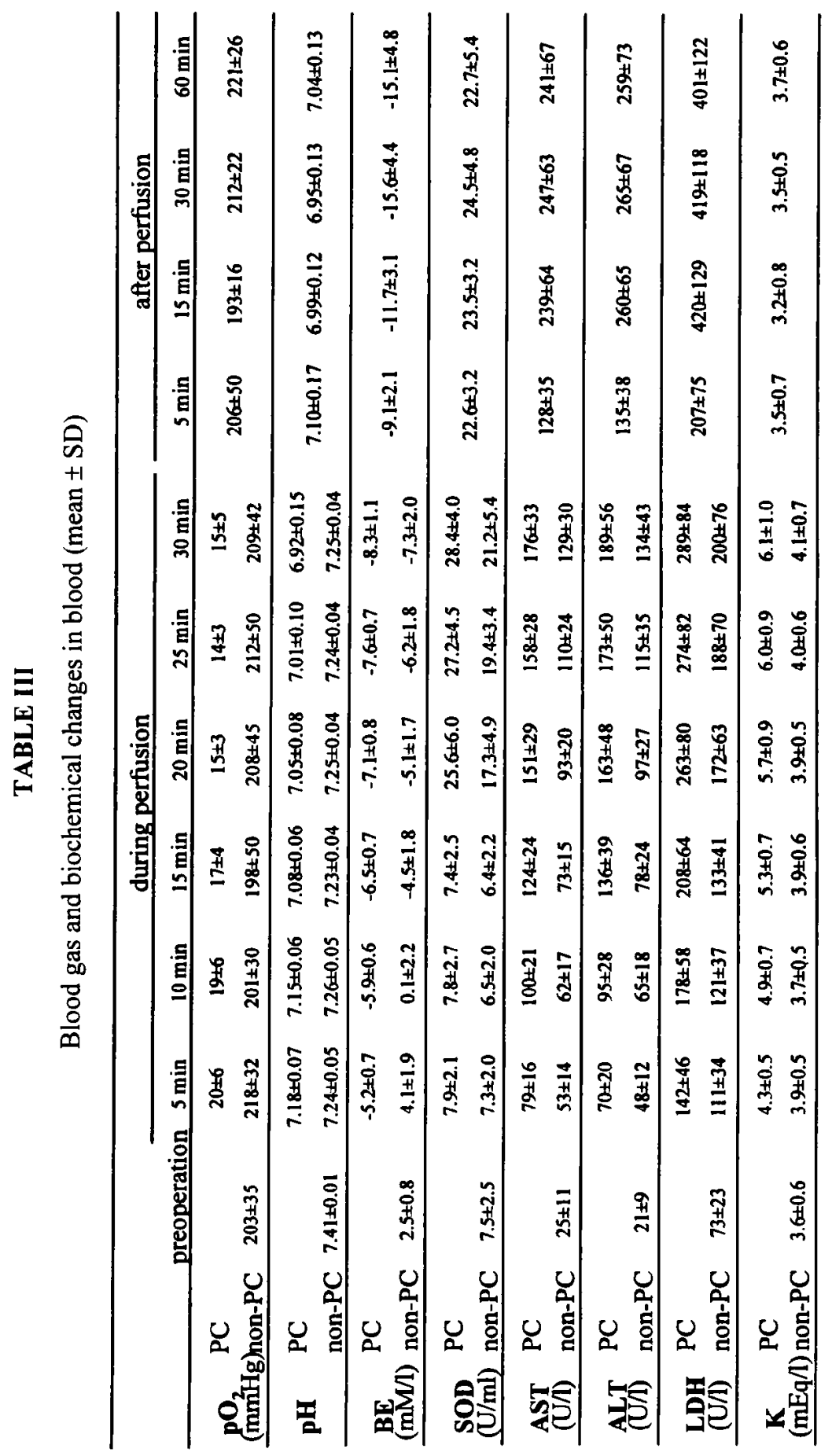




\section{ANNALS OF Cancer Research and Therapy}

In the ASI with HAP group, 5-FU concentrations $(\mu \mathrm{g} / \mathrm{g})$ in hepatic tissue 5 and 15 minutes after administration were $24.9 \pm 5.5,9.0 \pm 2.3$ and with the control group, $12.0 \pm 2.4,3.0 \pm 1.2$. In the ASI with HAP group, $5-\mathrm{FU}$ concentrations $(\mu \mathrm{g} / \mathrm{g})$ in pancreatic tissue were $36.6 \pm 6.3,27.5 \pm 5.5$, and with the control group, $16.2 \pm 4.0,9.0 \pm$ 3.0, respectively. In the ASI with HAP group, as compared to the controls, significantly high values were exhibited 5 and 15 minutes after administration in both hepatic and pancreatic tissue (Table II).

\section{Blood gas and biochemical kinetics}

All measurement results are shown in Table III.

p02; The preoperative value was $203 \pm 35 \mathrm{mmHg}$. For PC, the value during perfusion shifted with the range of $20 \pm 6$ to $14 \pm 3 \mathrm{mmHg}$. For non-PC, the value was in the range of $218 \pm 32$ to $198 \pm 50 \mathrm{mmHg}$. After completion of perfusion, the value was in the range of $221 \pm 26$ to $193 \pm 16 \mathrm{mmHg}$.

$\mathrm{pH}$; The preoperative value was $7.41 \pm 0.01$. For $\mathrm{PC}$, the value during perfusion dropped over time in the range of $7.18 \pm 0.07$ to $6.92 \pm 0.15$. For non- $\mathrm{PC}$, the value moved within the range of $7.26 \pm 0.05$ to $7.23 \pm 0.04$. After completion of perfusion, the value dropped over time down to $6.95 \pm 0.13$ after 30 minutes, then showed a slight recovery to $7.04 \pm 0.13$ after 60 minutes.

$\mathrm{BE}$; The preoperative value was $2.5 \pm 0.8 \mathrm{mM} / \mathrm{l}$. For $\mathrm{PC}$, the value during perfusion dropped over time in the range of $-5.2 \pm 0.7$ to $-8.3 \pm 1.1 \mathrm{mM} / 1$. For non-PC, the value dropped over time in the range of $4.1 \pm 1.9$ to $-7.3 \pm 2.0 \mathrm{mM} / \mathrm{l}$. After completion of perfusion, the value dropped over time down to $-15.6 \pm 4.4 \mathrm{mM} / \mathrm{l}$ after 30 minutes, but did not drop any further thereafter.

SOD; The preoperative value was $7.5 \pm 2.5 \mathrm{U} / \mathrm{ml}$. For PC, the value during perfusion moved within the range of $7.4 \pm 2.5$ to $28.4 \pm 4.0 \mathrm{U} / \mathrm{ml}$. During this period, the value exhibited a sharp rise from $7.4 \pm 2.5$ to $25.6 \pm 6.0 \mathrm{U} / \mathrm{ml}$ between 15 and 20 minutes after the start of perfusion. For non-PC, the value shifted within the range of $6.4 \pm 2.2$ to $21.2 \pm 5.4 \mathrm{U} / \mathrm{ml}$. During this period, the value exhibited a sharp rise from $6.4 \pm 2.2$ to $17.3 \pm 4.9 \mathrm{U} / \mathrm{ml}$ between 15 and 20 minutes after the start of perfusion. After completion of perfusion, the value shifted within the range of $22.6 \pm 3.2$ to $24.5 \pm 4.8 \mathrm{U} / \mathrm{ml}$. 
AST; The preoperative value was $25 \pm 11 \mathrm{U} / \mathrm{l}$. For PC, the value during perfusion rose over time in the range of $79 \pm 16$ to $176 \pm 33 \mathrm{U} / \mathrm{l}$. For non-PC, the value rose over time in the range of $53 \pm 14$ to $129 \pm 30 \mathrm{U} / 1$. After completion of perfusion, the value rose over time up to $247 \pm 63 \mathrm{U} / 1$ after 30 minutes, then showed a slight recovery to $241 \pm 67 \mathrm{U} / \mathrm{l}$ after 60 minutes.

ALT: The preoperative value was $21 \pm 9 \mathrm{U} / \mathrm{l}$. For PC, the value during perfusion rose over time in the range of $70 \pm 20$ to $189 \pm 56 \mathrm{U} / \mathrm{l}$. For non-PC, the value rose over time in the range of $48 \pm 12$ to $134 \pm 43 \mathrm{U} / \mathrm{l}$. After completion of perfusion, the value rose over time up to $265 \pm 67 \mathrm{U} / \mathrm{l}$ after 30 minutes, then showed a slight recovery to 259 $\pm 73 \mathrm{U} / 1$ after 60 minutes.

LDH; The preoperative value before was $73 \pm 23 \mathrm{U} / \mathrm{l}$. For PC, the value during perfusion rose over time in the range of $142 \pm 46$ to $289 \pm 84 \mathrm{U} / \mathrm{l}$. For non-PC, the value rose over time in the range of $111 \pm 34$ to $200 \pm 76 \mathrm{U} / \mathrm{l}$. After completion of perfusion, the value rose over time up to $420 \pm 67 \mathrm{U} / 1$ after 20 minutes, then showed a slight recovery to $401 \pm 122 \mathrm{U} / \mathrm{l}$ after 60 minutes.

$\mathrm{K}$ : The preoperative value was $3.6 \pm 0.6 \mathrm{mEq} / \mathrm{l}$. For $\mathrm{PC}$, the value during perfusion rose over time in the range of $4.3 \pm 0.5$ to $6.1 \pm 1.0 \mathrm{mEq} / \mathrm{l}$. For non-PC, the value was in the range of $3.7 \pm 0.5$ to $4.1 \pm 0.7 \mathrm{mEq} / \mathrm{l}$. After completion of perfusion, the value shifted within the range of $3.2 \pm 0.8$ to $3.7 \pm 0.6 \mathrm{mEq} / \mathrm{l}$.

These results were not statistically different from those in the ASI with HAP group without chemotherapy in both PC and non-PC.

\section{Discussion}

In order to increase the effectiveness of chemotherapy for cancer, several attempts have been performed to selectively elevate anticancer drug concentrations locally or to amplify the action of anticancer drugs. ASI with HAP is a new therapy to achieve these purposes by selectively elevating anticancer drug concentrations through local perfusion and by creating a hypoxic condition. For the clinical effect of ASI with HAP for advanced pancreatic cancer, Fiorentini, Poddie et al., (1996) reported that response rate was $50 \%$ at $\mathrm{CT}$ scan and $60 \%$ of all cases obtained significant reductions in 
markers base line level. They also commented that the duration of responses was $6.5 \pm$ 4.5 months (average: 8 months) and that the duration of survival was $9 \pm 4.5$ months (average: 12 months) for responders and $2 \pm 1$ months (average: 3 months) for nonresponders. It is very surprised that these results could be obtained by only once of ASI with HAP. Therefore, it is strongly suggested that the clinical effect of ASI with HAP may maintain for more than 6 months, if it should be repeatedly performed at least every 4 or 5 months as much as possible for responders.

From past reports using experimental tumors, it has become evident that the manifestations of anticancer drug action have differed according to the oxygenic environment surrounding tumor cells. Examples of anticancer drugs made stronger in action by oxygenic cells are bleomycin, actinomycin D and vincristine. Examples of drugs enhanced by hypoxia include MMC and Adriamycin. Among the drugs not dependent upon oxygenic conditions are 5-FU, CDDP and methotrexate (Teicher, Laso, et al., 1981). Yamagata, Kanematsu et al., (1992) reported that examples of anticancer drugs made stronger in action by hypoxic cells were MMC and Carboquone and that CDDP and Adriamycin were independent of oxygenic conditions. Tannock, 1987 reported that the antitumor effect of 5-FU was the same under oxygenation or hypoxia. Since there is no specificity in the cell cycle with short half-time, MMC is a suitable drug for local perfusion therapy in which the execution period is restricted (Fujita. 1982; van Hazel and Kovach, 1982; Rockwell, 1986; Sunada and Sano, 1966). Moreover, as noted previously, many investigators agree that the cytocidal action of $\mathrm{MMC}$ increases under a hypoxic environment. In chemotherapy for gastrointestinal cancer, 5-FU is widely used as a single drug or as a base drug in multi-drug therapy (Glimelius, 1998). It is suitable for ASI with HAP because half time is short and there is no weakening of antitumor effect in a hypoxic environment (Fujita, 1984). Based on these characteristics of drugs, we used MMC and 5-FU in this study and the doses of both drugs were set to be equivalent to regular doses when giving rapid intravenous injections to patients at clinical application.

From the results for blood concentrations of both MMC and 5-FU, the AUC with PC in the ASI with HAP group was significantly higher than in the control group and it is believed that this method is effective to increase the blood concentrations of 
anticancer drugs in the abdomen. On the other hand, there was no significant difference in AUC in the non-PC as compared with the control group. Averbach, Stuart et al., (1995) performed experiments of intraaortic stop-flow infusion on dog using 14C-labeled mitomycin by means of open abdominal vessel clamp and reported that in portal vein blood (PC) AUC was significantly higher in comparison to the control group regardless of vessel clamp position, but that in cutaneous vein blood (non-PC) there was no significant difference. Shiraha and Sakai (1965) reported that abdominal perfusion was performed using MMC and that the systemic exsorption rate in 40 minutes after the start of perfusion was $48 \%$. Iwasaki (1968) reported that radioactive iodinated serum albumin (RISA) was administered in abdominal perfusion and the systemic exsorption rate in 40 minutes after perfusion was $45 \%$. Concerning the chronological changes of concentrations in our results, we found that exsorption of drugs from PC to non-PC began immediately after administration. Although exsorption rates cannot simply be calculated from drug concentrations in PC and non-PC because of the differences of drug type, dose, metabolism and metabolic route, it was clarified that many anticancer drugs leaked to non-PC in a short duration. This phenomenon is thought to be exsorption from the small branches of the aorta. Shiraha and Sakai (1965) also reported that anticancer drugs in the perfusion area leaked into the systemic blood flow according to the abundant collateral circulation, even if the main blood vessels were clamped. From these findings, it is suggested that the maximum dose of anticancer drugs in ASI with HAP should not greatly exceed the dose given in systemic administration by rapid intravenous injection.

To our knowledge, there were no past reports to be measured tissue concentrations of anticancer drugs under this method. In our results for both MMC and 5FU, hepatic and pancreatic concentrations in the ASI with HAP group were significantly higher than those in the control group. This method is thought to be the most effective in elevating concentrations of anticancer drugs in abdominal tissues. Concentrations of MMC and 5-FU in hepatic tissue were lower than those in pancreatic tissue and there was a tendency for the concentration in hepatic tissue to decline more rapidly in comparison to pancreatic tissue. This is ascribed to the fact that the catabolism of both agents occur mainly in the liver (Fujita, 1982; Fujita, 1984). 
The measurements of blood gas indicated that a hypoxic condition was maintained only in PC and PC became lower in $\mathrm{pH}$ during perfusion. As mentioned previously, the action of MMC is enhanced under hypoxic conditions. Tomasz, Lipman et al., (1985) reported that action was enhanced even under low $\mathrm{pH}$ conditions. The active mechanism of MMC is that it can bind with the DNA of tumor cells, and can block replication of DNA by forming a cross-link to double stranded DNA, then can suppress tumor division (Szybalski and Iyer, 1964). Tomasz, Lipman et al., (1985) clarified that when intracellular $\mathrm{pH}$ became low, the number of DNA cross-links by MMC increased, and that the cellular survival rate decreased according to the increase of cross-links. From these findings, ASI with HAP is regarded as a method of selectively sensitizing the action of MMC in the abdomen.

The results of blood biochemical examinations revealed that the variations in each parameter peaked between 15 and 30 minutes after completion of perfusion and that they all reached a plateau 60 minutes after completion. The increases of hepatic enzymes such as AST, ALT and LDH were ascribed to ischemia due to the aorta stop-flow and to the reperfusion injury of the liver following release of stop-flow (Thurman, Marzi, et al., 1988). SOD exhibited a sharp increase immediately after administration of anticancer drugs, which was ascribed to the influence of MMC administration. Lown, Begleiter et al., (1976) reported that free radical scavengers such as SOD or catalase inhibited the DNA suppressed action of MMC, suggesting that free radicals might play an important role in MMC action. Klein, Berkenstadt et al., (1994) investigated circulatory kinetics in ASI with HAP and reported that the clamping and declamping of aorta brought significant changes in average blood pressure, $\mathrm{EtCO} 2$ and cardiac output, but these were all reversible changes. In light of the aforementioned, biochemical changes in ASI with HAP were believed to be reversible and of short duration.

\section{References}

Aigner, K.R. (1993). Aortic stopflow infusion (ASI) and hypoxic abdominal perfusion (HAP) for disseminated bulky peritoneal carcinomatosis-rationale and technique. Reg. Cancer. Treat. 6 (Suppl 1): 3.

Aigner, K. R. and Gailhofer, S. (1993). Celiac axis infusion (MMC, CDDP, 5-FU) and aortic stop-flow infusion vs. abdominal hypoxic perfusion (MMC) in UICC stage III/IV pancreatic cancer-48 patients. Reg. Cancer. Treat. 6 (Suppl 1): 2. 
Aigner, K. R. and Kaevel, K. (1994). Pelvic stopflow infusion (PSI) and hypoxic pelvic perfusion (HPP) with mitomycin and melphalan for recurrent rectal cancer. Reg. Cancer. Treat. 7: 6-11.

Averbach, A. M., Stuart, O. A., and Sugarbake, T. A. (1995). Pharmacokinetic studies of intraaortic stop-flow infusion with 14C-labeled mitomycin C. J. Surg. Res. 59: 415-419.

Creech,O. Jr., Krementz.E.T. Ryan, R. F., and Winblad, J.N. (1958). Chemotherapy of cancer : regional perfusion utilizing an extracorproreal circuit. Ann. Surg. 148: 616-632.

Fiorentini, G., Poddie, D., Ricci, S., Leoni, M., Cantore, M., Graziani, G., Dazzi, C., Rossi, G., Guglielminetti, D. and Roversi, R. (1996). Intra-aortic stop-flow infusion (IASFI) with hypoxic abdominal perfusion (HAP) in UICC stage III/IV pancreatic carcinoma (PC): report of a phase II study. Reg. Cancer. Treat. 9: 8891.

Fujimori, M., Sakauchi, G., Izumio, M., Morita,S., Anzai, T. and Sadamitsu, H. (1963). Regional perfusion chemotherapy and arterial infusion of anticancer drugs: with special references to the breast cancer and gastric cancer. Operation. 17: 477-484.

Fujita, H. (1982). Pharmacokinetics of mitomycin C (MMC) and 7-N-(PHydroxyphenyl)- mitomycin C (KW-2083). Jan. J. Cancer. Chemother. 9: 13621373.

Fujita, H. (1984). Pharmacokinetics of fluoropyrimidines. Jan. J. Cancer. Chemother. 11: 2307-2315.

Glimelius, B. (1998). Chemotherapy in the treatment of cancer of the pancreas. J. Hepatobiliary. Pancreat. Surg. 5: 235-241.

van Hazel, G. A. and Kovach, J. S. (1982). Pharmacokinetics of mitomycin C in rabbit and human. Cancer. Chemother. Pharmacol. 8: 189-192.

Idezuki, Y. and Miura, T. (1990). Implantable drug delivery system. Operation. 44: 841848.

Iwasaki, T. (1965). Studies of regional perfusion using anti-cancer drugs. J. Niigata Med. 82: 79-196.

Klein, E. S., Berkenstadt, H., Koller, M., Papa, M. Z., Ben-Ari, Lieberman, N. and Perel, A. (1994). Hemodynamic effects of aortic stop flow and total abdominal ischemic perfusion. Reg. Cancer. Treat. 2: 82-85.

Ku, Y., Saitoh, M., Tominaga, M., Iwasaki, T., Maekawa, Y., Shiki, H., and Saitoh, Y. (1991). A new method of intraarterial high dose chemotherapy for unresectable hepatomas using hemoperfusion under hepatic venous isolation (HVI/DHP). J.Jpn.Surg.Soc. 92: 1338-1341.

Lown, J.W., Begleiter, A., Johnson. D. and Morgan, A. R. (1976). Studies related to antitumor antibiotics, Part V. Reaction of mitomycin C with DNA examined by ethidium fluorescence assay. Can. J. Biochem. 54: 110-119.

Miura, T., Idezuki, Y. and Wada, T. (1985). Intraarterial infusion chemotherapy for hepatic carcinomas using a totally implantable infusaid pump. Jan.J.Cancer.Chemother. 12: 1949-1961.

Miura, T. (1989). Arterial infusion chemotherapy for hepatoma with implantable drug delivery system. Kan Tan Sui. 18: 243-249. 
Rockwell,S. (1986). Effects of some proliferative and environmental factors on the toxicity of MMC to the tumor cells in vitro. Int. J. Cancer. 38: 229-235.

Roversi, R., Ricci, S., Rossi, G., Cavallo, G., Roversi, M., and Fiorentini, G. (19961998). Percutaneous technique for antiblastic stop-flow perfusions in advanced tumors: a three years experience. Reg. Cancer. Treat. 9: 196-201.

Sakauchi, G., Ukishima, J., Atusmi, K., Sakurai, Y., Fujimori, Y, Abe, M., Azuma, H., Tateishi, A., Mikami, R. and Iwakura, H. (1963). Studies on cancer chemotherapy by regional perfusion (preliminary Report). Jpn.J.Cancer.Clin. 9: 59-65.

Shiraha, Y. and Sakai, K. (1965). Chemotherapeutic tumor perfusion. Surgical Treatment 12: $579-588$.

Sunada, T. and Sano, S. (1966). Regional chemotherapy of anticancer agents Surgical Clinic 8: 527-531.

Szybalski, W. and Iyer, V. N. (1964). Crosslinking of DNA by enzymaticaly or chemically activated mitomycins and porfiromycins, bifunctionally galkylating hantibiotics. Fed. Proc. 23: 946-957.

Tannock, I. F. (1987). Toxicity of 5-fluorouracil for aerobic and hypoxic cells in two murine tumors. Cancer. Chemother. Pharmacol. 19: 53-56.

Teicher, B.A., Laso, J.S. and Sartorelli, A. C. (1981). Classification of @antineoplastic agents by their selective toxicities toward oxygenate and hypoxic tumor cells. Cancer. Res. 41: 73-81.

Thompson, J. F., Liu, M., Waugh, R. C., Watson, L. D., Sheldon, D.M., Stephen, M. S., Storey, D. W. and Kam, P. C. A. (1994). A percutaneous aortic g stop-flow h infusion technique for regional cytotoxic therapy of abdomen and pelvis. Reg. Cancer. Treat. 7: 202-207.

Thurman, R. G., Marzi, I. and Seitz, G. (1988). Hepatic reperfusion injury following orthotopic liver transplantation in the rat. Transplantation. 46: 502-506.

Tomasz, M., Lipman, R., Verdine, G. L. and Nakanishi, K. (1985). Nature of the destruction of deoxyguanosine residues by mitomycin $\mathrm{C}$ activated by mild acid pH. J. Am. Chem. Soc. 107: 6120-6121.

Yamagata, M., Kanematu, T., Matumata, T., Utumomiya, T., Ikeda, Y. and Keizo, S. (1992). The difference in chemosensitivity to antineoplastic agents of human hepatocellular carcinoma under normo-oxygenated or hypoxic conditions. Eur. J. Surg. Oncol. 18: 379-382.

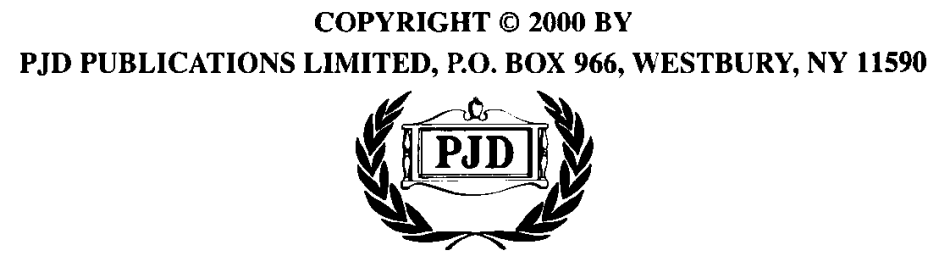

